Research Article

\title{
Mechanical and Mesoscale Analyses of Cement Stabilized Macadam Prepared by Vibratory and Nonvibratory Mixing Techniques
}

\author{
Jijing Wang $\mathbb{D}^{1}$ and Zhihua Tan $\mathbb{D}^{2}$ \\ ${ }^{1}$ School of Traffic \& Transportation Engineering, Changsha University of Science \& Technology, Changsha 410004, China \\ ${ }^{2}$ Changsha University of Science \& Technology, Changsha 410004, China
}

Correspondence should be addressed to Zhihua Tan; luck@csust.edu.cn

Received 16 December 2020; Revised 18 January 2021; Accepted 1 February 2021; Published 10 February 2021

Academic Editor: Pengfei Liu

Copyright ( 92021 Jijing Wang and Zhihua Tan. This is an open access article distributed under the Creative Commons Attribution License, which permits unrestricted use, distribution, and reproduction in any medium, provided the original work is properly cited.

\begin{abstract}
The objective of this study is to analyze the effects of mixing techniques on the mechanical behavior and meso-structure of cementtreated aggregate. Different specimens were prepared by vibratory and nonvibratory mixing techniques. X-ray CT scans were performed to illustrate the distribution of cement mortar on aggregate. The strength, modulus, and fatigue tests under different stress states were tested to reveal the impacts of mixing techniques. Then, the relationships between strengths and loading rates and that between moduli and stress levels were established. Hereafter, the S-N fatigue equation that modified with stress ratio related to loading rates was used to describe the fatigue performance. The results indicate that the cement mortar of specimens prepared by vibratory mixing was well-distributed on aggregates. The strength, modulus, and fatigue life of the specimens prepared by vibratory mixing were higher under the test condition threshold. Moreover, the growth rate of strength and modulus with loading for specimens prepared by vibratory mixing was slightly larger than that for specimens prepared by nonvibratory mixing. Compared with the cement-treated aggregates specimens prepared by nonvibratory mixing, the fatigue life of cementtreated aggregates specimens prepared by vibratory mixing had more stable stress sensitivity.
\end{abstract}

\section{Introduction}

The semirigid asphalt pavement is one of the leading asphalt pavement types in China, taking advantage of strong bearing capacity, high integrity, and satisfactory capacity to distribute upper loads $[1,2]$. More than $90 \%$ of the bases of semirigid asphalt pavements in China use cement-treated aggregates $[3,4]$. Cement-treated aggregates are generally preferred materials for the semirigid base due to its high overall strength, high stiffness, good moisture susceptibility, desirable fatigue resistance performances, and readily available raw materials $[5,6]$. Cement-treated aggregates are usually prepared with aggregates of a suitable gradation and 3\%-8\% cement at the optimum water to cement ratio. The development of the strength of cement-treated aggregates is affected by the properties of constituent materials as well as the mixing technique [7-9].

The reflection cracks are the primary distress of semirigid base asphalt pavement $[10,11]$. In the literature, numerous studies were conducted to improve the pavement performance of cement-treated aggregates [12-14]. The influence of raw materials, cement content, and additives on the road performance of cement-treated aggregates was investigated. Microscopic analyses were also performed to optimize materials and design $[15,16]$. Ngoc Kien Bui et al. [17] proposed a new method that replaces natural aggregate (NA) with different percentages of recycled aggregate (RA). It was found that the combination of RA and NA could significantly improve the mechanical properties of recycled aggregate concrete (RAC) compared with the traditional method. Federico Autelitano et al. [18] replaced part of the 
aggregates in cement-treated aggregates with the electric arc furnace (EAF) slag. The authors stated that the compacted effect, durability, and mechanical properties of the modified mixture were significantly improved. . Eziefula et al. [19] developed a new green concrete, i.e., shell aggregate concrete, which could be used as nonstructural and low-strength ordinary concrete. All results of the above studies showed that the mechanical properties of cement-treated aggregates are closely related to the aggregate properties. William Fedrigo et al. [20] used indirect tensile tests, triaxial tests, and bending tests to evaluate the effects of cement content, curing time, and compressive strength on the strength and stiffness of cement-treated aggregates. The results showed that the cement content had the most significant influence on the strength and stiffness of cement-treated aggregates among the above factors. Xuan et al. [21] established a parameter prediction model to characterize the mechanical properties of cement-treated aggregates. The authors reported that the unconfined compressive strength parameters could reflect the change of the mechanical properties of cement-treated aggregates. And, the unconfined compressive strength was mainly affected by the cement content, curing time, and degree of compaction. Therefore, the mechanical properties of cement-treated aggregates are closely related to cement content, and the impacts of cement content, curing time, and compaction could not be ignored.

Besides, many scholars have shown that the type, structure, and parameters of mixers significantly affect the mixing uniformity, mixing efficiency, and hardening behavior of mixtures [22-24]. Vibratory mixing has become a popular technique for stirring concrete. Shen et al. [25] introduced different types of vibratory mixing techniques and gave the comparison among those mixing methods. Zhao et al. [26] used the vibratory mixing technique to form cement-treated aggregates specimens based on orthogonal test designs. It was found that the mixing time had the most noteworthy influence on the compressive strength of cement-treated aggregates, the vibration frequency and mixing speed was second, and the wet mixing time had the least impact [27]. Jiang et al. [28] compared the road performance of cement-treated aggregates prepared by the vibratory method and static method and showed that the vibratory method-prepared specimens were closer to engineering practice. Zhang et al. [29-31] conducted long-term experimental research on the vibratory mixing of cement-treated aggregates. They stated that the vibratory mixing technique had a good wrapping effect on the coarse aggregate over traditional mixing technique so that cement-treated aggregates were more evenly mixed. And, they also found that the vibratory mixing technique could effectively improve the microscopic uniformity of cement-treated aggregates materials. Thus, this technique can promote a variety of dynamic effects of cement-treated aggregates materials, improve the structure formation process of concrete, and significantly improve the quality and efficiency of mixing. In the process of vibratory mixing, the mixing behavior realizes the macroscopic cyclic movement of the mixture, the purpose of which is to combine the materials; the vibratory behavior is used to accelerate the diffusion movement, the intention of which is to mix the materials evenly [25, 32]. However, only a few researchers have revealed the influence mechanism of the mixing process on the road performance of cement-treated aggregates, and the research related to the influence of the mixing process on the mechanical properties of cement-treated aggregates materials is even insufficient.

Therefore, in this paper, the research has been conducted to verify the improving effects of vibratory mixing techniques from the perspective of mechanics and mesoscale structures. The influence of mixing techniques on the pavement performance of materials was demonstrated. $\mathrm{X}$-ray CT scans were carried to analyze the meso-structure of two different types of cement-treated aggregate specimens. The cement mortar and its wrapping effect under different mixing processes were also compared. Then, the strength, modulus, and fatigue test of two different types of cementtreated aggregate specimens under different stress states were conducted under different loading rates. At the same time, the relationships between strength, modulus, and loading rates were established. The $\mathrm{S}-\mathrm{N}$ fatigue equation associated with the loading rate was applied to characterize the fatigue properties of cement-treated aggregates.

\section{Materials and Test Methods}

\subsection{Materials and Mixture Design}

2.1.1. Cement. The PSB32.5R cement was used in this paper, and its properties are tested and shown in Table 1. It can be seen from the test results that the properties of the cement satisfied the requirements of the Technical Guidelines for Construction of Highway Road bases (JTG/T F20-2015) (2015).

2.1.2. Aggregate. According to the source of local mineral materials, limestone was selected as the raw material for cement-treated aggregates. The properties of limestone aggregates were tested according to the Chinese Test Methods of Aggregate for Highway Engineering (JTG E42-2005) (2005); the test results are listed in Table 2.

The gradation of aggregates is a crucial factor determining the mechanical properties of cement-treated aggregate. According to the Chinese Technical Guidelines for Construction of Highway Road bases (JTJ/T F20-2015) (2015), the gradation was selected based on the optimum service performance of the cement-treated aggregates; the gradation curve of limestone aggregates is shown in Figure 1.

2.1.3. Mixture Proportion Design. The PSB32.5R cement with different contents (i.e., 3\%, 3.5\%, 4\%, 4.5\%, and 5\%) and limestone aggregates with the target gradation (Figure 1) was used to prepare cement-treated aggregates. Based on the requirements of Chinese Test Methods of Materials Stabilized with Inorganic Binders for Highway Engineering (JTG E51-2009) (2009), the vibration compaction test was applied to determine the maximum dry density and optimum moisture content of the mixture. The test results are presented in Table 3; the maximum dry density of cement- 
TABLE 1: Properties of PSB32.5R cement.

\begin{tabular}{lccr}
\hline & Property & Value & Technical requirement \\
\hline Fineness & & 2.1 & $\leq 10$ \\
Stability $(\mathrm{mm})$ & & 3 & $\leq 5$ \\
$\mathrm{MgO}$ content (\%) & & 2.9 & $\leq 5$ \\
$\mathrm{SO}_{3}$ content (\%) & 3 days & 1.2 & $\leq 3.5 \%$ \\
Compressive strength of cement mortar (MPa) & 28 days & 24.9 & $\geq 10$ \\
& Initial setting & 28.5 & - \\
Setting time (min) & Final setting & 410 & $\geq 180$ \\
& & & $\geq 360$ \\
\hline
\end{tabular}

TABle 2: Properties of limestone aggregate.

\begin{tabular}{|c|c|c|c|c|c|}
\hline \multirow{2}{*}{ Property } & \multirow{2}{*}{ Technical requirement } & \multicolumn{4}{|c|}{ Test result of coarse aggregate } \\
\hline & & $19 \sim 31.5 \mathrm{~mm}$ & $9.5 \sim 19.5 \mathrm{~mm}$ & $4.75 \sim 9.5 \mathrm{~mm}$ & $0 \sim 4.75 \mathrm{~mm}$ \\
\hline Content of flat and elongated particles (\%) & $\leq 20 \%$ & 11.7 & 15.8 & - & - \\
\hline Crushing value (\%) & $\leq 26 \%$ & 21.3 & 18.9 & - & - \\
\hline Bulk volume relative density $\left(\mathrm{g} / \mathrm{cm}^{3}\right)$ & - & 2.230 & 2.730 & 2.607 & 2.589 \\
\hline Apparent density $\left(\mathrm{g} / \mathrm{cm}^{3}\right)$ & - & 2.821 & 2.763 & 2.731 & 2.692 \\
\hline Water absorption (\%) & - & 0.4 & 0.6 & 1.3 & - \\
\hline Liquid limit of particles smaller than $0.6 \mathrm{~mm}$ & $\leq 28 \%$ & \multicolumn{4}{|c|}{$23 \%$} \\
\hline Plastic index of particles smaller than $0.6 \mathrm{~mm}$ & $\leq 9$ & \multicolumn{4}{|c|}{3.2} \\
\hline
\end{tabular}

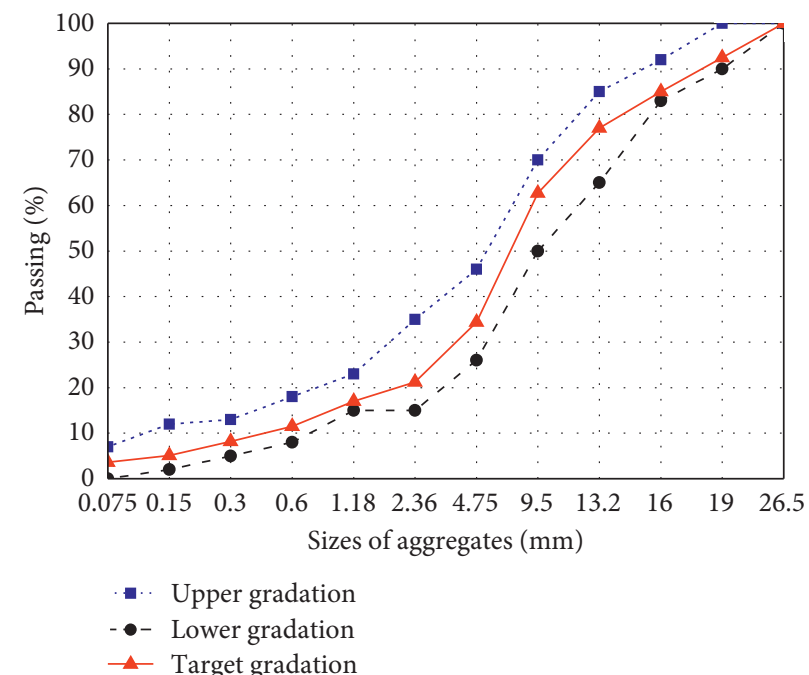

Figure 1: Gradation curve of limestone aggregates.

TABLE 3: Vibration compaction test results of cement-treated aggregates.

\begin{tabular}{lcc}
\hline Cement content $(\%)$ & Maximum dry density $\left(\mathrm{g} / \mathrm{cm}^{3}\right)$ & Optimum moisture content $(\%)$ \\
\hline 3.0 & 2.380 & 4.9 \\
3.5 & 2.398 & 4.8 \\
4.0 & 2.413 & 4.8 \\
4.5 & 2.429 & 4.8 \\
5.0 & 2.431 & 4.9 \\
\hline
\end{tabular}

treated aggregates increased with the cement content, but when the cement content exceeded $4.5 \%$, the increasing amplitude decreased obviously. Thus, the optimum cement content of $4.5 \%$ was calculated, and the corresponding optimum moisture content and maximum dry density were $4.8 \%$ and $2.429 \mathrm{~g} / \mathrm{cm}^{3}$, respectively.
2.2. Specimen Preparation. In order to analyze the influence of mixing techniques on the mechanical properties of cement-treated aggregates, the raw materials were mixed by the DETONG mixing equipment, which contained both vibratory and nonvibratory modes. And, the specimens were prepared using vibration compaction equipment. 
Aggregates were sieved and then dried in an oven. After that, certain amounts of water, cement, and aggregate were mixed using the DETONG mixing equipment in the vibratory or nonvibratory mode for $40 \mathrm{~s}$. The vibratory frequency is determined based on the natural frequency of cementtreated aggregate for the purpose of resonance, and the amplitude is $0.5 \sim 2 \mathrm{~mm}$. And then, cement-treated aggregate specimens with two different mixing techniques were prepared in the mold under vibratory compaction.

According to the requirements of Chinese Test Methods of Materials Stabilized with Inorganic Binders for Highway Engineering (JTG E51-2009) (2009), beam specimens with sizes of $150 \mathrm{~mm} \times 150 \mathrm{~mm} \times 550 \mathrm{~mm}$ and cylindrical specimens with height of $150 \mathrm{~mm}$ and diameter of $150 \mathrm{~mm}$ were prepared. Among them, the beam specimens were prepared for four-point bending tests, and cylindrical specimens were prepared for unconfined compression tests and indirect tensile tests. After demolding, the specimens that met the requirements were stored in a standard curing room (the relative humidity of not less than $95 \%$ and the temperature of $20 \pm 2^{\circ} \mathrm{C}$ ) for 90 days, as shown in Figure 2.

2.3. Test Design. In this study, $\mathrm{X}$-ray $\mathrm{CT}$ was chosen to investigate the meso-structure of cement-treated aggregates prepared with different mixing techniques. The specimens were scanned with spacing of $0.9 \mathrm{~mm}$ at the voltage of $220 \mathrm{kV}$ and the electric current of 10-40 mA.

The strength, modulus, and fatigue tests were performed to examine the effect of mixing techniques on the mechanical performances of cement-treated aggregates. Indirect tensile tests were carried out using the Material Test System (MTS) equipment. Loading rates of $5 \mathrm{MPa} / \mathrm{s}$, $10 \mathrm{MPa} / \mathrm{s}, 20 \mathrm{MPa} / \mathrm{s}, 30 \mathrm{MPa} / \mathrm{s}, 40 \mathrm{MPa} / \mathrm{s}$, and $50 \mathrm{MPa} / \mathrm{s}$ were considered in the strength tests. Modulus tests were conducted using a staged loading method, and the stress levels were $0.25 \mathrm{MPa}, 0.5 \mathrm{MPa}, 1 \mathrm{MPa}$, and $1.5 \mathrm{MPa}$. The indirect tensile fatigue tests under stress-control mode and the halfsine load with a frequency of $10 \mathrm{~Hz}$ and the stress levels were 0.25 $\mathrm{MPa}, 0.5 \mathrm{MPa}, 1 \mathrm{MPa}$, and 1.5 MPa. Unconfined compression tests and four-point bending tests were also carried out using the MTS equipment, and the test method was similar to that for the indirect tensile test. The loading rates of $5 \mathrm{MPa} / \mathrm{s}, 10 \mathrm{MPa} / \mathrm{s}, 20 \mathrm{MPa} / \mathrm{s}, 30 \mathrm{MPa} / \mathrm{s}, 40 \mathrm{MPa} / \mathrm{s}$, and $50 \mathrm{MPa} / \mathrm{s}$ were also considered in unconfined compression tests and four-point bending tests. The stress levels used in four-point bending tests were consistent with those in indirect tensile tests. Since the loading rate for unconfined compression tests was too large, the stress levels were set at 3.5 $\mathrm{MPa}, 6 \mathrm{MPa}, 8 \mathrm{MPa}$, and $10 \mathrm{MPa}$ to ensure the safety and operability of the test. Five replicate samples were used for each test.

\section{Results and Analyses}

3.1. Effects of Mixing Techniques on the Strength. Cement-treated aggregates specimens were prepared by vibratory and nonvibratory techniques. Then, the specimens were tested by MTS under three different stress states to determine the strength. In this paper, the indirect tensile, unconfined compression tests, and four-point bending tests were chosen for the strength test.

In indirect tensile tests and unconfined compression tests, the loading rate was $1 \mathrm{~mm} / \mathrm{min}$. While the loading rate was $50 \mathrm{~mm} / \mathrm{min}$ in four-point bending tests. The above choices were based on the Test Methods of Materials Stabilized with Inorganic Binders for Highway Engineering (JTG E51-2009) (2009).

The test results are shown in Figure 3.

It is noted from Figure 3 that the standard strength of the specimens prepared by vibratory mixing was higher than that of the specimens prepared by nonvibratory mixing. Under the standard test condition, the unconfined compressive strength $(11.76 \mathrm{MPa})$ of the vibratory mixed specimen was about $18 \%$ larger than that $(9.98 \mathrm{MPa})$ of nonvibratory mixed specimen; the indirect tensile strength $(1.30 \mathrm{MPa})$ of the vibratory mixed specimen was about $15 \%$ higher than that $(1.13 \mathrm{MPa})$ of nonvibratory mixed specimen; the bending tensile strength $(1.31 \mathrm{MPa})$ of the vibratory mixed specimen was about $12 \%$ higher than that $(1.17 \mathrm{MPa})$ of nonvibratory mixed specimen. This indicates that the vibratory mixing has a more significant effect on the increase of unconfined compressive strengths of cement-treated aggregates.

In order to investigate the relationship between the strength and loading rate of specimens prepared by vibratory and nonvibratory mixing under three different stress states, different loading rates were applied in the tests. Three sets of parallel tests were carried out at the same loading rate, and the relationship curves between strength and loading rate of three different stress states are presented in Figures 4-6.

Figures 4-6 show that the vibratory mixing had a more significant influence on the bending strength with the increased loading rate. As the loading rate continued to grow, both the unconfined compressive strength and the indirect tensile strength increase tended to be gentle.

Meanwhile, by comparing the parallel test strength results of the specimens prepared by vibratory and nonvibratory mixing, the coefficient of variation $C_{v}$ is shown in Table 4 . It can be found that vibratory mixing can significantly reduce the coefficient of variation, which indicates that the cement-treated aggregates prepared by vibratory mixing had higher strength stability than the cement-treated aggregates prepared by nonvibratory mixing.

3.2. Effects of Mixing Techniques on the Modulus. The specimens were prepared by vibratory and nonvibratory techniques. Then, the specimens were applied to determine the modulus of cement-treated aggregates by MTS under three different stress states. In this paper, the indirect tensile tests, unconfined compression tests, and four-point bending tests were chosen for the modulus test.

According to the Test Methods of Materials Stabilized with Inorganic Binders for Highway Engineering (JTG E512009) (2009), the loading rate for standard modulus tests was $1 \mathrm{~mm} / \mathrm{min}$ in indirect tensile tests, unconfined compression tests, and four-point bending tests. The MTS obtained the 

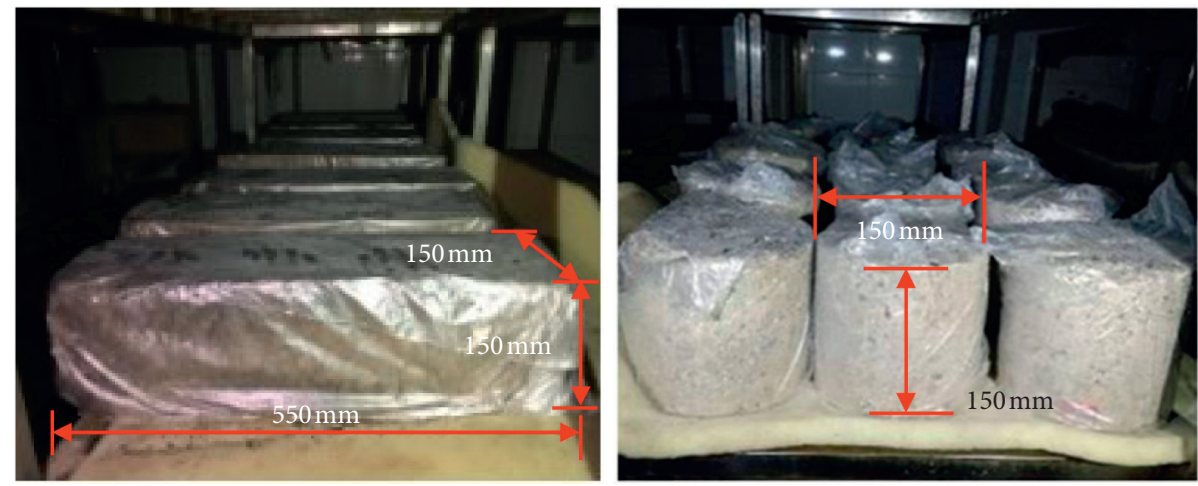

FIgURe 2: Preparation of cement-treated aggregate specimens.

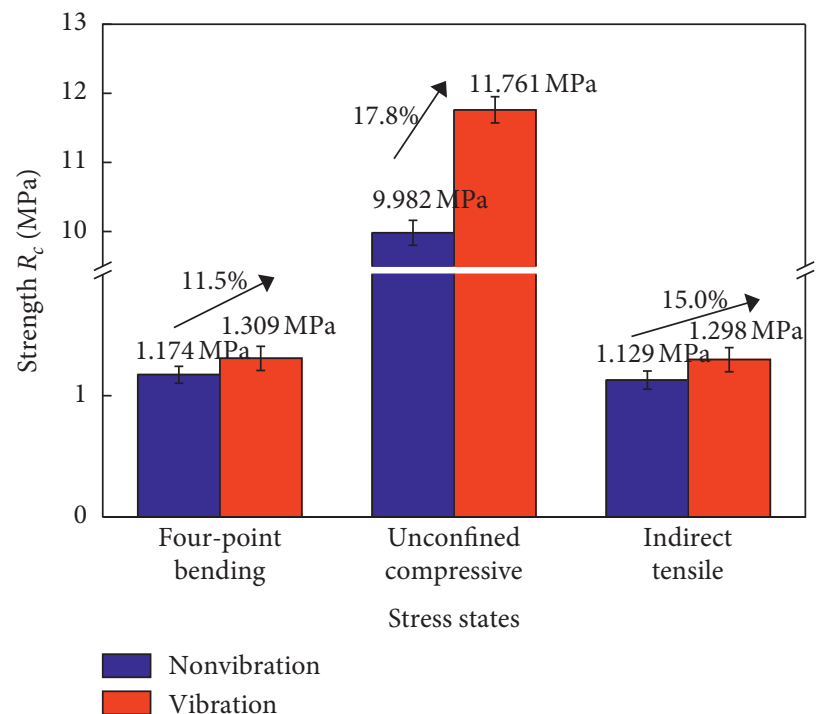

FIGURE 3: Standard strength of vibratory and nonvibratory mixed specimens under different stress states.

calculation data of cement-treated aggregate material modulus under three different stress states. The unconfined compressive modulus, the indirect tensile modulus, and the four-point bending modulus of specimens were calculated by using equations (1)-(3), respectively:

$$
E_{c}=\frac{p h}{l}
$$

where $E_{c}$ is the unconfined compressive modulus of the specimen $(\mathrm{MPa}) ; p$ is the unit pressure $(\mathrm{MPa}) ; h$ is the height of the specimen $(\mathrm{mm}) ; l$ is the rebound deformation of the specimen $(\mathrm{mm})$ :

$$
E_{i}=\frac{p-p_{0}}{d l_{x}}(0.27-1.0 \mu)
$$

where $E_{i}$ is the indirect tensile modulus of the specimen $(\mathrm{MPa}) ; p$ is the load level $(\mathrm{N}) ; p_{0}$ is the initial load $(\mathrm{N}) ; d$ is the diameter of the specimen $(\mathrm{mm})$; and $l_{x}$ is the horizontal rebound deformation of the specimen $(\mathrm{mm}) ; \mu$ is Poisson ratio:

$$
E_{s}=\frac{23 L\left(p-p_{0}\right)^{3}}{108 \times b \times h^{3} \times l},
$$

where $E_{s}$ is the four-point bending modulus of the specimen $(\mathrm{MPa}) ; p$ is the load level $(\mathrm{N}) ; p_{0}$ is the minimum load $(\mathrm{N}) ; L$ is the span of the specimen ( $\mathrm{mm}) ; l$ is the midspan rebound deformation ( $\mathrm{mm})$; bis the width of the midspan ( $\mathrm{mm})$; and $h$ is the height of the midspan (mm).

Figure 7 presents the standard modulus of vibratory and non-vibratory specimens under different stress states. It is noted that the standard modulus of the specimens prepared by vibratory mixing was higher than that of the specimens prepared by nonvibratory mixing. Under the standard test condition, the unconfined compressive modulus $(16996 \mathrm{MPa})$ of the vibratory mixed specimen was about $22 \%$ larger than that $(13913 \mathrm{MPa})$ of nonvibratory mixed specimen; the indirect tensile modulus (11507 MPa) of the vibratory mixed specimens was about $20 \%$ larger than that (9608 MPa) of nonvibratory mixed specimen; the bending tensile modulus $(1976 \mathrm{MPa})$ of the vibratory mixed specimen was about $13 \%$ larger than that $(1754 \mathrm{MPa})$ of nonvibratory mixed specimen. It was found that the vibratory mixing has a 


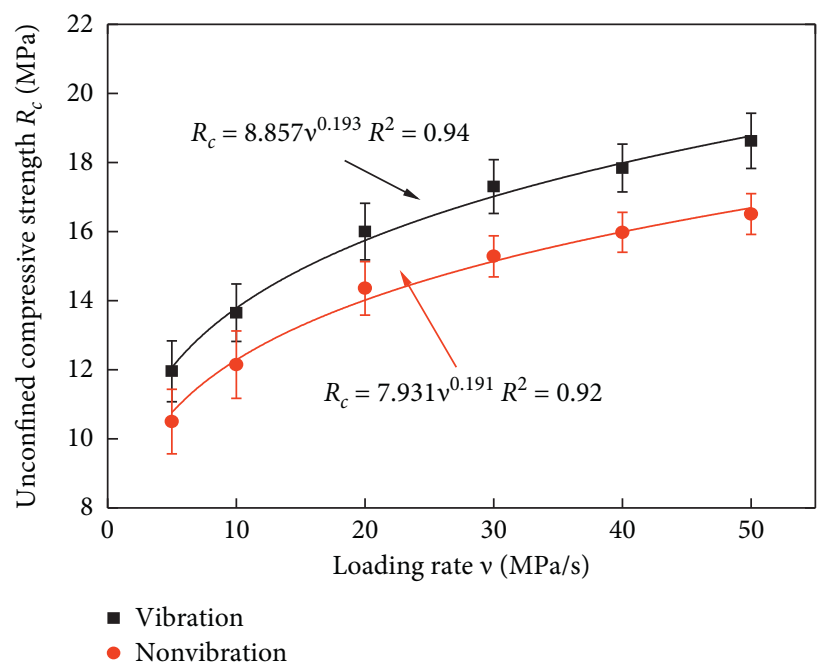

FIGURE 4: Unconfined compressive strength of cement-treated aggregates affected by loading rates.

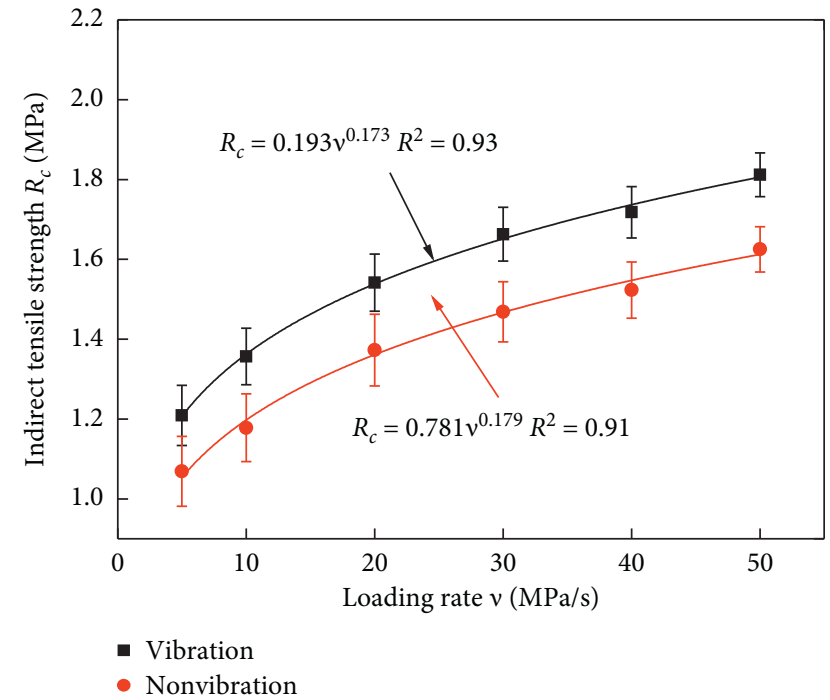

FIGURE 5: Indirect tensile strength of cement-treated aggregates affected by loading rates.

more significant influence on the increase of the standard modulus of cement-treated aggregates.

In order to explore the relationship between the modulus and stress level of cement-treated aggregates specimens prepared by vibratory and nonvibratory mixing under three different stress states, different stress levels were applied in each stress state. And, the modulus tests were performed using a staged loading mode. Four sets of parallel specimens were tested at the same stress level. The relationships between the modulus and the stress level under three different stress states are illustrated in Figures 8-10. It can be noted that as the stress level increased under each stress state, the modulus decreased with a linear function. The linear function equation was as follows:

$$
E=k \sigma+m,
$$

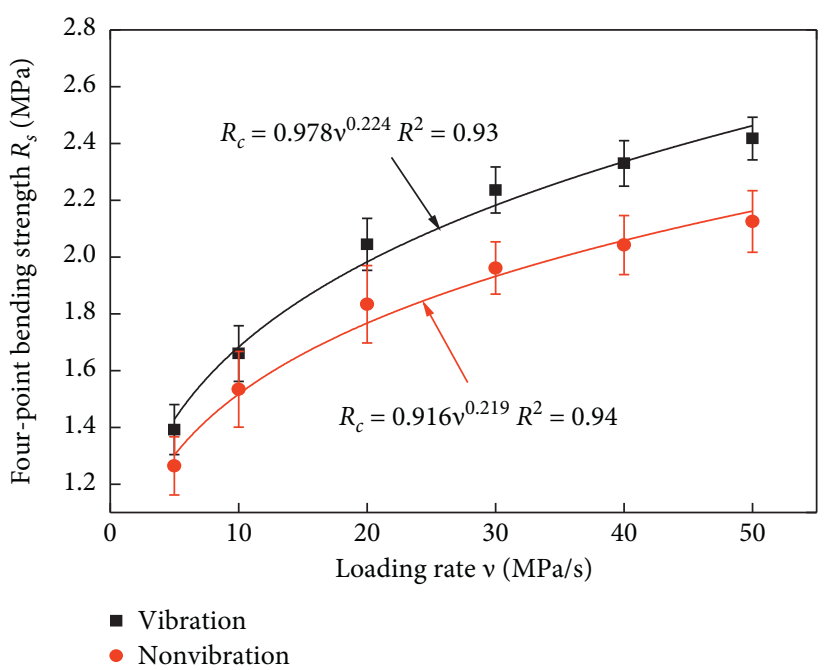

FIGURE 6: Bending tensile strength of cement-treated aggregates affected by loading rates.

where $E$ is the modulus of the specimen (MPa); $\sigma$ is the stress level (MPa); and $k$ and $m$ are the fitting parameters (see Table 5).

Figures $8-10$ show that, with the increase in stress level, the vibratory mixing had a more positive influence on the attenuation of the unconfined compressive modulus. As the stress level continued to grow, the mitigation of indirect tensile modulus and bending tensile modulus under vibratory conditions was also gradually accelerated, which was slightly better than the attenuation of the tensile modulus under nonvibratory conditions.

The coefficient of variation $C_{v}$ of modulus results of specimens prepared by vibratory and nonvibratory mixing is shown in Table 6. It is noted that the coefficient of variation of the modulus of the specimen prepared by vibratory mixing was lower than that of the specimen prepared by nonvibratory mixing. In other words, the vibratory mixing 
TABLE 4: Coefficient of variation of strengths of specimens prepared by vibratory and nonvibratory mixing under different stress states.

\begin{tabular}{|c|c|c|c|c|}
\hline \multirow{2}{*}{ Loading rate $(\mathrm{MPa} / \mathrm{s})$} & \multirow{2}{*}{ Mixing method } & \multicolumn{3}{|c|}{ Coefficient of variation $C_{v}(\%)$} \\
\hline & & Unconfined compression & Indirect tensile & Bending tensile \\
\hline \multirow{2}{*}{5} & Vibration & 7.36 & 6.18 & 6.32 \\
\hline & Nonvibration & 8.91 & 8.22 & 8.04 \\
\hline \multirow{2}{*}{10} & Vibration & 5.04 & 5.15 & 5.82 \\
\hline & Nonvibration & 8.02 & 7.24 & 8.71 \\
\hline \multirow{2}{*}{20} & Vibration & 4.17 & 4.62 & 3.94 \\
\hline & Nonvibration & 5.42 & 6.58 & 7.47 \\
\hline \multirow{2}{*}{30} & Vibration & 3.53 & 4.02 & 3.14 \\
\hline & Nonvibration & 3.92 & 5.15 & 4.69 \\
\hline \multirow{2}{*}{40} & Vibration & 2.65 & 3.76 & 3.41 \\
\hline & Nonvibration & 3.65 & 4.65 & 5.09 \\
\hline \multirow{2}{*}{50} & Vibration & 3.41 & 3.02 & 2.91 \\
\hline & Nonvibration & 3.58 & 3.54 & 5.12 \\
\hline
\end{tabular}

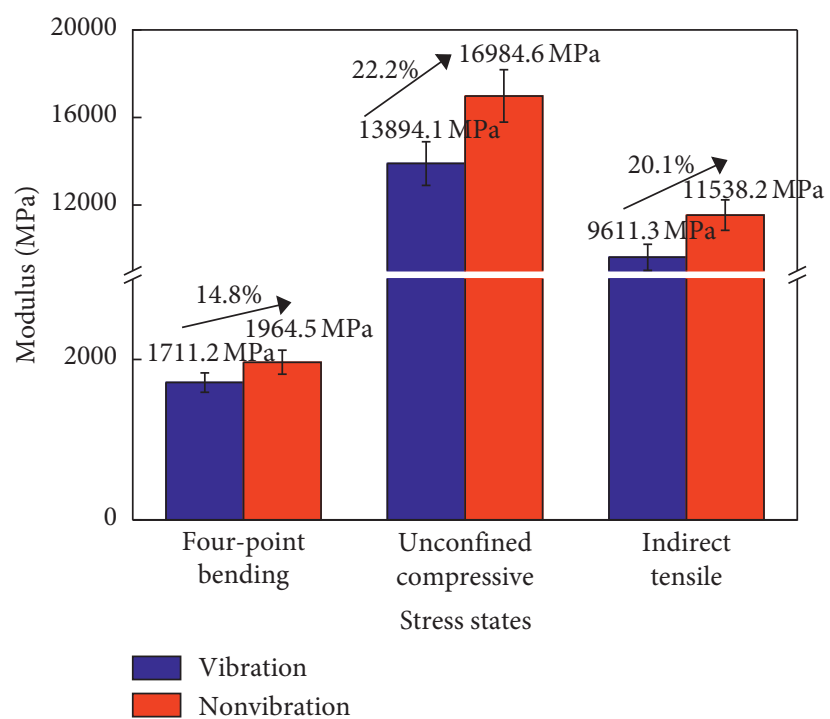

Figure 7: Standard modulus of vibratory and nonvibratory mixed specimens under different stress states.

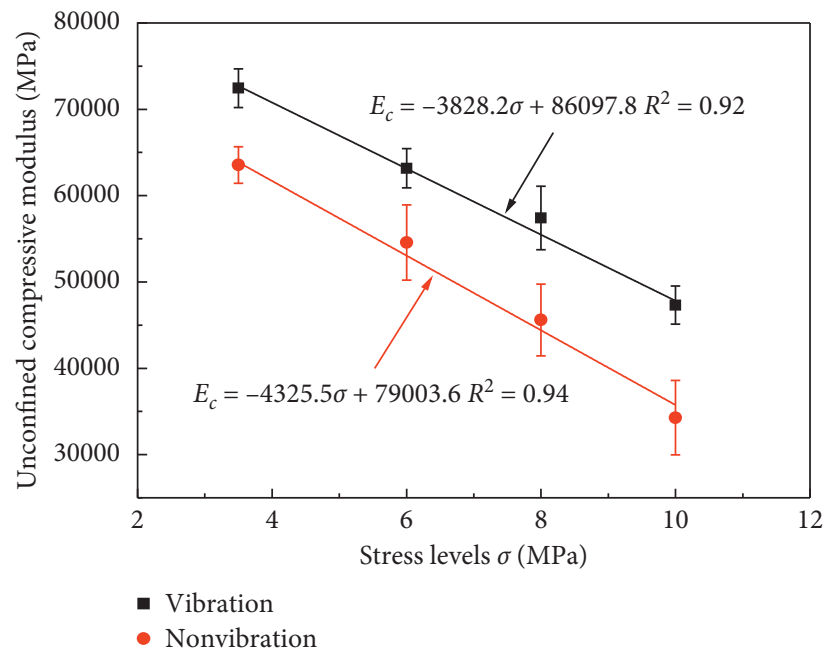

FIGURE 8: Unconfined compressive modulus of cement-treated aggregates affected by stress levels. 


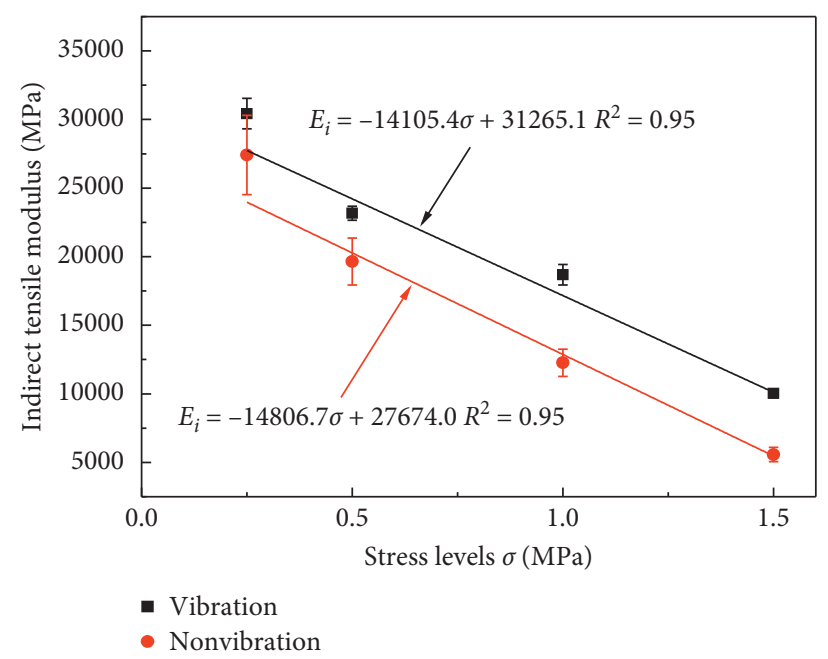

Figure 9: Indirect tensile modulus of cement-treated aggregates affected by stress levels.

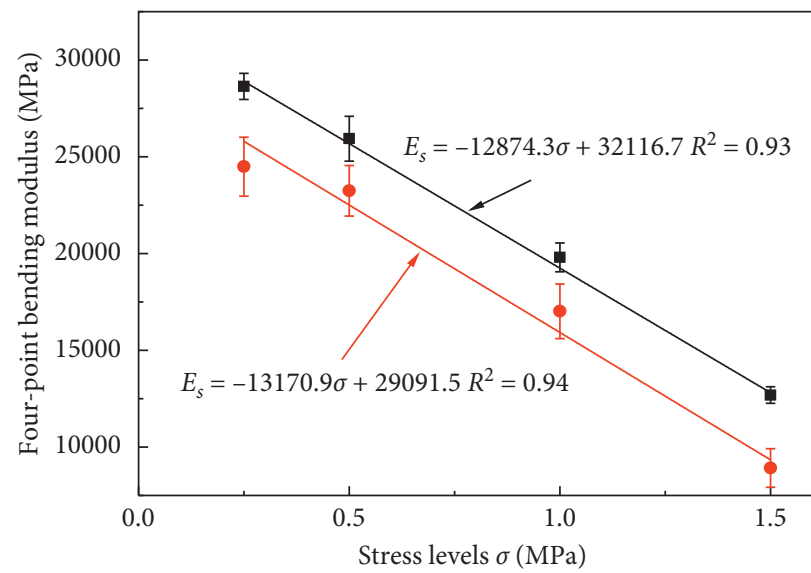

- Vibration

- Nonvibration

FigURE 10: Four-point bending modulus of cement-treated aggregates affected by stress levels.

TABLE 5: Coefficients of variation of fatigue lives under different stress states.

\begin{tabular}{|c|c|c|c|c|}
\hline \multirow{2}{*}{ Stress level (MPa) } & \multirow{2}{*}{ Mixing method } & \multicolumn{3}{|c|}{ Coefficient of variation $C_{\mathrm{v}}(\%)$} \\
\hline & & Indirect tensile & Four-point bending & Unconfined compression \\
\hline \multirow{2}{*}{0.25} & Vibration & 8.88 & 6.73 & - \\
\hline & Nonvibration & 9.62 & 10.56 & - \\
\hline \multirow{2}{*}{0.5} & Vibration & 6.84 & 9.29 & - \\
\hline & Nonvibration & 8.18 & 10.36 & - \\
\hline \multirow{2}{*}{1.0} & Vibration & 5.61 & 6.09 & - \\
\hline & Nonvibration & 7.72 & 7.70 & - \\
\hline \multirow[b]{2}{*}{1.5} & Vibration & 4.31 & 3.44 & - \\
\hline & Nonvibration & 5.06 & 4.72 & - \\
\hline \multirow{2}{*}{3.5} & Vibration & - & - & 9.65 \\
\hline & Nonvibration & - & - & 11.97 \\
\hline \multirow{2}{*}{6} & Vibration & - & - & 8.0 \\
\hline & Nonvibration & - & - & 7.85 \\
\hline \multirow{2}{*}{8} & Vibration & - & - & 4.28 \\
\hline & Nonvibration & - & - & 8.36 \\
\hline \multirow{2}{*}{10} & Vibration & - & - & 4.83 \\
\hline & Nonvibration & - & - & 7.37 \\
\hline
\end{tabular}


TABLE 6: Coefficient of variation of the modulus test results of specimens prepared by vibratory and nonvibratory mixing.

\begin{tabular}{|c|c|c|c|c|}
\hline \multirow{2}{*}{ Stress level (MPa) } & \multirow{2}{*}{ Mixing method } & \multicolumn{3}{|c|}{ Coefficient of variation $C_{v}(\%)$} \\
\hline & & Indirect tensile & Four-point bending & Unconfined compression \\
\hline \multirow{2}{*}{0.25} & Vibration & 3.32 & 2.36 & - \\
\hline & Nonvibration & 9.83 & 6.21 & - \\
\hline \multirow{2}{*}{0.5} & Vibration & 2.01 & 4.46 & - \\
\hline & Nonvibration & 7.57 & 5.64 & - \\
\hline \multirow{2}{*}{1.0} & Vibration & 4.75 & 3.75 & - \\
\hline & Nonvibration & 7.47 & 8.29 & - \\
\hline \multirow{2}{*}{1.5} & Vibration & 4.00 & 3.35 & - \\
\hline & Nonvibration & 7.85 & 8.38 & - \\
\hline \multirow{2}{*}{3.5} & Vibration & - & - & 3.10 \\
\hline & Nonvibration & - & - & 3.33 \\
\hline \multirow{2}{*}{6} & Vibration & - & - & 3.66 \\
\hline & Nonvibration & - & - & 7.58 \\
\hline \multirow{2}{*}{8} & Vibration & - & - & 6.62 \\
\hline & Nonvibration & - & - & 8.04 \\
\hline \multirow{2}{*}{10} & Vibration & - & - & 5.22 \\
\hline & Nonvibration & - & - & 11.89 \\
\hline
\end{tabular}

had better adaptability and stability than the nonvibratory mixing.

3.3. Fatigue Test Results and Analysis. According to the Test Methods of Materials Stabilized with Inorganic Binders for Highway Engineering (JTG E51-2009) (2009), the stresscontrol mode and the continuous half-sine load with frequency of $10 \mathrm{~Hz}$ were used for the standard fatigue tests. And then, unconfined compression tests, indirect tensile tests, and four-point bending tests were carried out on the specimens with different mixing techniques. The unconfined compressive strength of the vibratory mixed specimen was $11.76 \mathrm{MPa}$, and the corresponding maximum load was $207.82 \mathrm{kN}$. By contrast, the unconfined compressive strength of the nonvibratory mixed specimen was $9.98 \mathrm{MPa}$, and the corresponding maximum load was $176.36 \mathrm{kN}$. Similarly, the indirect tensile strength of the vibratory mixed specimen was 1.298 MPa, and the corresponding maximum load was $46.60 \mathrm{kN}$. The indirect tensile strength of the nonvibratory specimen was $1.129 \mathrm{MPa}$, and the corresponding maximum load was $40.53 \mathrm{kN}$. The four-point bending strength of the vibratory specimen was $1.309 \mathrm{MPa}$, and the corresponding maximum load was $9.820 \mathrm{kN}$. The four-point bending strength of the nonvibratory specimen was $1.174 \mathrm{MPa}$, and the corresponding maximum load was $8.805 \mathrm{kN}$. And then, the standard strength test results under three different stress states were used as the standard fatigue test parameters, respectively. The selected stress ratio was 0.6 according to the specification (2009), and the fatigue test results are shown in Figure 11.

It is observed that under standard conditions the fatigue life of the specimens prepared by vibratory mixing was higher than that of the specimens prepared by nonvibratory mixing (Figures 11). Under the standard test condition (from 1060966 times to 1296586 times), the unconfined compressive fatigue life of the vibrating specimens was increased by about $22 \%$. Under the standard test condition (from 177355 times to 205411 times), the indirect tensile fatigue life of the vibrating specimens was increased by about $16 \%$. Under the standard test condition (from 195864 times to 230538 times), the bending tensile fatigue life of the vibrating specimens was increased by about $18 \%$. It is found that the vibratory mixing was more significant for the fatigue life under standard conditions increase of unconfined compressive fatigue test results.

In order to investigate the variation of fatigue life of specimens at different stress levels, the unconfined compression tests, indirect tensile tests, and four-point bending fatigue tests were carried out regarding standard fatigue test procedures. The real stress ratio was obtained by the following equation:

$$
t_{s}=\frac{\sigma}{R_{c}}
$$

where $t_{s}$ is the stress ratio related to loading rates; $\sigma$ is the stress level (MPa); and $R_{c}$ is the strength corresponding to the stress level (MPa).

The fatigue life results and the real stress ratio were fitted by equation (6) in double logarithmic coordinates, as shown in Figures 12-14:

$$
\lg N_{f}=a-k t_{s},
$$

where $N_{f}$ is the fatigue life of the specimen; $t_{s}$ is the real ratio; and $a, k$ are the fitting parameters.

Figures 12-14 show that the unconfined compressive, indirect tensile, and four-point bending fatigue life of the cement-treated aggregate varied significantly with the real stress ratio.

It is noted that the $k$ value of the vibratory mixed specimen was significantly smaller than that of the nonvibratory mixed specimen. This indicates that vibratory mixing was able to alleviate the fatigue failure of the cementtreated aggregates under any stress state. 


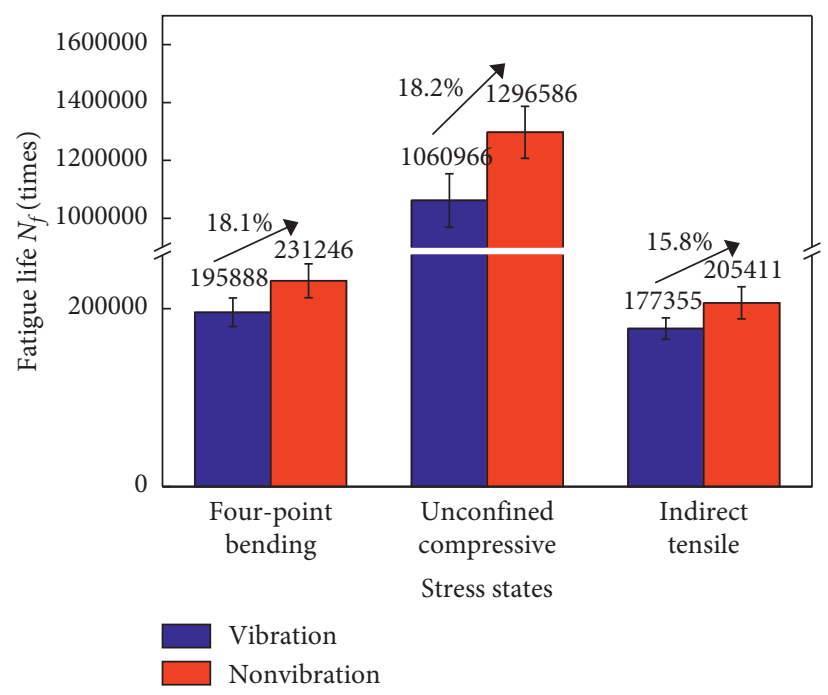

FIGURE 11: Standard fatigue life of vibratory and nonvibratory mixed specimens under different stress states.

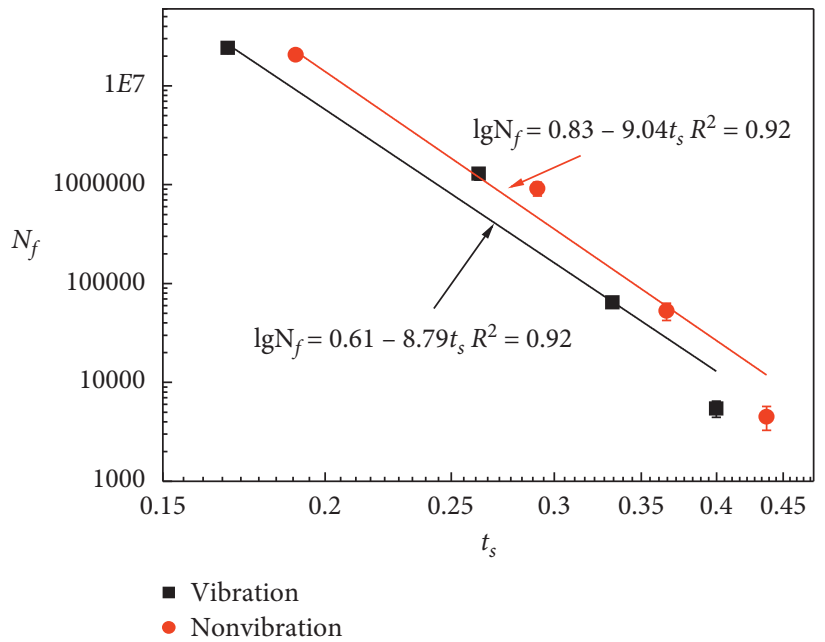

FIGURE 12: Unconfined compressive fatigue curve based on real stress ratio of specimens prepared with different mixing techniques.

The coefficients of variation $C_{v}$ of fatigue life results are shown in Table 6. It is found that vibratory mixing can significantly reduce the coefficient of variation, which indicates that the cement-treated aggregates of the vibratory mixed specimen had better stress sensitivity in terms of fatigue performance than that of the nonvibratory mixed specimen.

3.4. X-Ray CT Test Results and Analysis. The cement-treated aggregate is a loose multiphase composite material, which has obvious nonuniform characteristics. Generally, it is easy to produce weak surfaces in the interior due to the uneven distribution of cementitious material and aggregate.
In order to study the dispersion of internal materials of cement-treated aggregates prepared by different mixing techniques, X-ray CT tests were carried out on the cylindrical specimens cured for 90 days. The X-ray CT test results of the circular cross section are shown in Figure 15.

It is observed that the specimens prepared by nonvibratory mixing had many voids between coarse aggregates. In other words, the voids were not filled by fine aggregates. By contrast, the specimens prepared by vibratory mixing had fewer voids and higher compactness. Fine aggregates in nonvibratory mixed specimens exhibited serious agglomeration. Because of the agglomeration of fine aggregates around coarse aggregates, coarse aggregates could be better wrap. Since the emergence of the phenomenon of agglomeration, the coarse aggregates cannot be fully wrapped. 


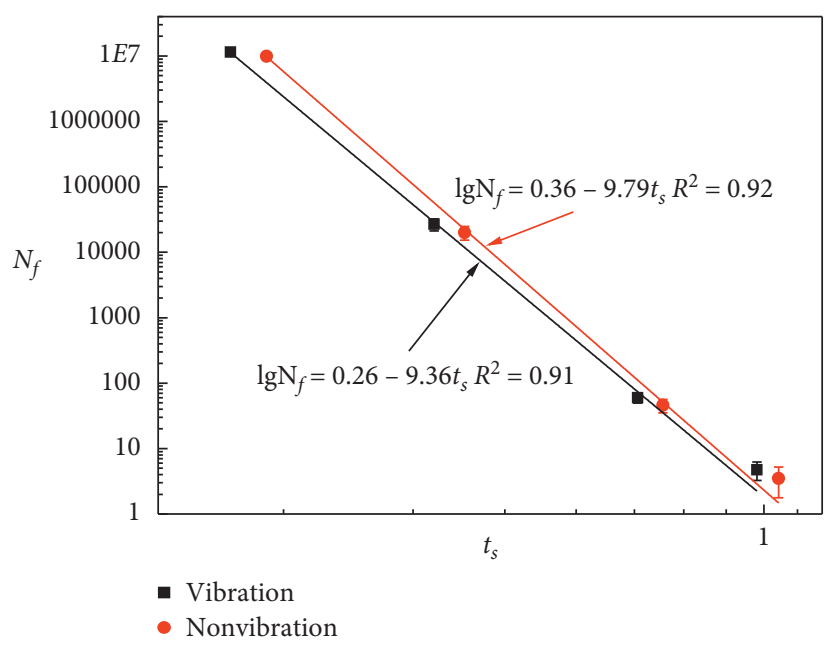

FIgURE 13: Indirect tensile fatigue curve based on real stress ratio of specimens prepared by different mixing techniques.

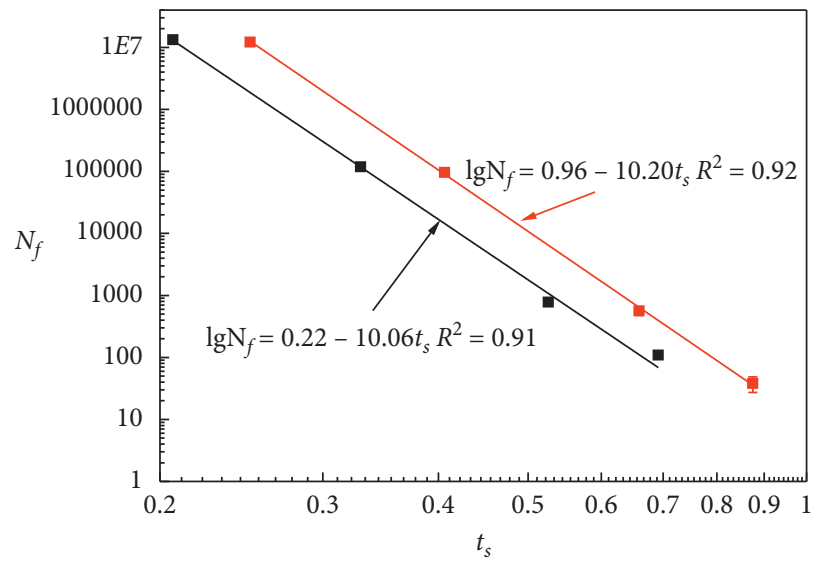

- Vibration

- Nonvibration

Figure 14: Four-point bending fatigue curve based on real stress ratio of specimens prepared by different mixing techniques.
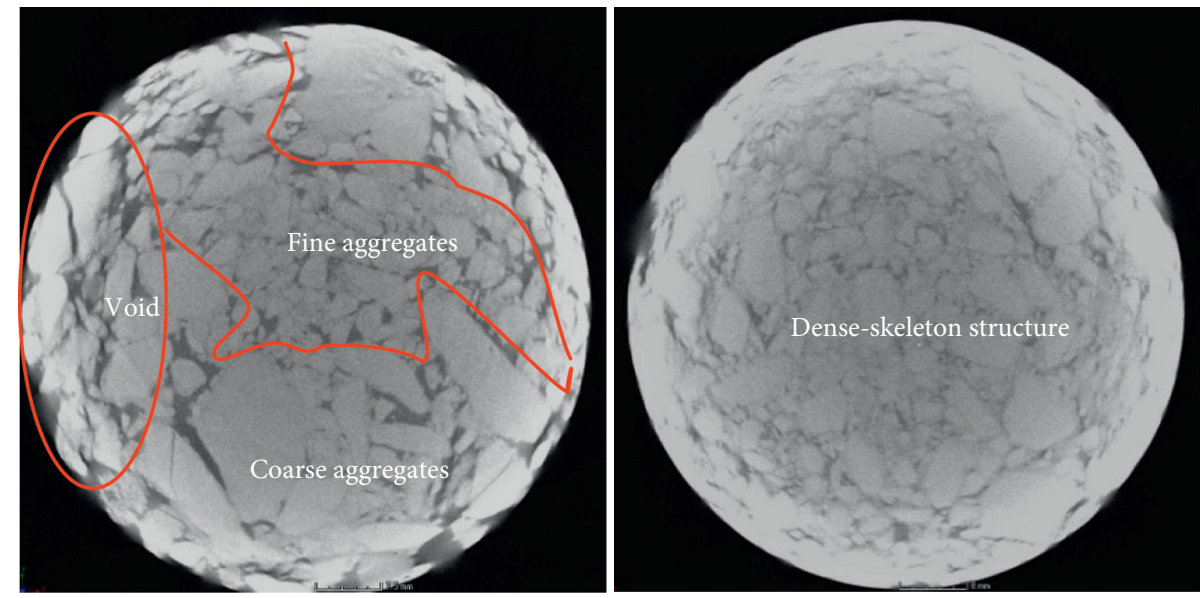

FIgURE 15: The X-ray CT test results of the circular cross section of cement-treated aggregates prepared by different mixing techniques. 


\section{Conclusions}

In this study, the strength, modulus, and fatigue life of cement-treated aggregates specimens prepared by different mixing techniques were tested. Meanwhile, the mesostructure of cement-treated aggregates was analyzed by $\mathrm{X}$-ray CT. The following conclusions can be drawn from this study:

(1) Compared with the nonvibratory mixing technique, the vibratory mixing technique enables cementtreated aggregates to have higher strength, modulus, and fatigue life. Moreover, the vibratory mixing techniques for improving unconfined compressive strength, modulus, and fatigue life were significantly higher than the other two stress state, which will facilitate its promotion and application.

(2) Vibratory mixing technique significantly weakened the agglomeration of fine aggregates, so coarse aggregates could be sufficiently wrapped by fine aggregates. Thereby the overall compactness of cement-treated aggregates was much improved by vibratory mixing.

(3) Further work could be focused on establishing the relationship between the microscopic characteristics and the mechanical properties of cement-treated aggregates.

\section{Data Availability}

The data used to support the findings of this study are available from the corresponding author upon request.

\section{Conflicts of Interest}

The authors declare that they have no conflicts of interest.

\section{Acknowledgments}

This work was supported by the National Natural Science Foundation of China (Grant nos. 51838001 and 51908069).

\section{References}

[1] Y. Zheng, P. Zhang, Y. Cai, Z. Jin, and E. Moshtagh, "Cracking resistance and mechanical properties of basalt fibers reinforced cement-stabilized macadam," Composites Part B: Engineering, vol. 165, pp. 312-334, 2019.

[2] Q. Li, Z. Wang, Y. Li, and J. Shang, "Cold recycling of lime-fly ash stabilized macadam mixtures as pavement bases and subbases," Construction and Building Materials, vol. 169, pp. 306-314, 2018.

[3] Y. Sun and L. Li, "Strength assessment and mechanism analysis of cement stabilized reclaimed lime-fly ash macadam," Construction and Building Materials, vol. 166, pp. 118-129, 2018.

[4] T. Huang, S. Qi, H. Liu, H. Yu, and S. Li, "Shear properties of asphalt mixtures under triaxial compression," Applied Sciences, vol. 9, no. 7, p. 1489, 2019.

[5] L. Song, Z. Song, C. Wang, X. Wang, and G. Yu, "Arch expansion characteristics of highway cement-stabilized macadam base in Xinjiang, China," Construction and Building Materials, vol. 215, pp. 264-274, 2019.

[6] A.-M. Sha, "Material characteristics of semi-rigid base," China Journal of Highway and Transport, vol. 97, no. 1, pp. 1-5, 2008.

[7] C. Deng, Y. Jiang, H. Lin, and X. Ji, "Mechanical-strengthgrowth law and predictive model for cement-stabilized macadam," Construction and Building Materials, vol. 215, pp. 582-594, 2019.

[8] S. H. Chu, "Effect of paste volume on fresh and hardened properties of concrete," Construction and Building Materials, vol. 218, pp. 284-294, 2019.

[9] T. Hemalatha, K. R. Ram Sundar, A. R. Murthy, and N. R. Iyer, "Influence of mixing protocol on fresh and hardened properties of self-compacting concrete," Construction and Building Materials, vol. 98, pp. 119-127, 2015.

[10] C. Liu and S. Lv, "Analysis and comparison of different impacts of aging and loading frequency on fatigue characterization of asphalt concrete," Journal of Materials in Civil Engineering, vol. 32, no. 9, Article ID 04020240, 2020.

[11] C. Liu and S. Lv, "Normalized characterization method for fatigue behavior of cement treated aggregates based on the yield criterion," Construction and Building Materials, vol. 228, pp. 1-9, 2019.

[12] S. Du, "Influence of chemical additives on mixing procedures and performance properties of asphalt emulsion recycled mixture with reclaimed cement-stabilized macadam," Construction and Building Materials, vol. 118, pp. 146-154, 2016.

[13] W. Li, L. Lang, Z. Lin, Z. Wang, and F. Zhang, "Characteristics of dry shrinkage and temperature shrinkage of cement-stabilized steel slag," Construction and Building Materials, vol. 134, pp. 540-548, 2017.

[14] S. Lv, C. Liu, J. Lan, H. Zhang, J. Zheng, and Z. You, "Fatigue equation of cement-treated aggregate base materials under a true stress ratio," Applied Sciences, vol. 8, no. 5, p. 691, 2018.

[15] C. Liu, S. Lv, D. Jin, and F. Qu, "Laboratory investigation for the road performance of asphalt mixtures modified by rock asphalt/styrene butadiene rubber," Journal of Materials in Civil Engineering, vol. 33, no. 3, p. 04020504, 2021.

[16] J. Marchand, "The microstructures of dry concrete products," Cement and Concrete Research, vol. 26, no. 3, 1996.

[17] S. Lv, Y. Jiang, and X. Peng, "Standardization to evaluate the lasting capacity of rubberized asphalt mixtures with different testing approaches," Construction and Building Materials, vol. 32, Article ID 121341, 2020.

[18] F. Autelitano and F. Giuliani, "Electric arc furnace slags in cement-treated materials for road construction: mechanical and durability properties," Construction and Building Materials, vol. 113, pp. 280-289, 2016.

[19] U. G. Eziefula, J. C. Ezeh, and B. I. Eziefula, "Properties of seashell aggregate concrete: a review," Construction and Building Materials, vol. 192, pp. 287-300, 2018.

[20] W. Fedrigo, W. P. Núñez, M. A. Castañeda López, T. R. Kleinert, and J. A. P. Ceratti, "A study on the resilient modulus of cement-treated mixtures of RAP and aggregates using indirect tensile, triaxial and flexural tests," Construction and Building Materials, vol. 171, pp. 161-169, 2018.

[21] C. Xia, "Unified characterizing fatigue performance of rubberized asphalt mixtures subjected to different loading modes," Journal of Cleaner Production, vol. 23, 2021.

[22] J. Dils, G. De Schutter, and V. Boel, "Influence of mixing procedure and mixer type on fresh and hardened properties of concrete: a review," Materials and Structures, vol. 45, no. 11, pp. 1673-1683, 2012. 
[23] C. F. Ferraris, "Concrete mixing methods and concrete mixers: state of the art," Journal of Research of the National Institute of Standards and Technology, vol. 106, no. 2, pp. 391-399, 2001.

[24] P.-K. Chang and Y.-N. Peng, "Influence of mixing techniques on properties of high performance concrete," Cement and Concrete Research, vol. 31, no. 1, pp. 87-95, 2001.

[25] H. Shen, Z. S. Duan, and F. Li, "The evaluation about vibratory mixing methods," Applied Mechanics and Materials, vol. 219, pp. 2678-2682, 2012.

[26] L. Zhao, "Influence of mixing methods on performance of compressive strength for cement stabilized macadam mixture," China Journal of Highway and Transport, vol. 31, no. 1, pp. 151-158, 2018.

[27] J. Xue and Y. Jiang, "Analysis on the fatigue properties of vertical vibration compacted lime-fly ash-stabilized macadam," Construction and Building Materials, vol. 155, pp. 531-541, 2017.

[28] Y.-J. Jiang, "Road performance and composition design of cement-ash stabilized aggregate of dense framework structure," Journal of Chang'an University (Natural Science Edition), vol. 5, pp. 1-4, 2008.

[29] L. Zhang and Z. Feng, "Process of concrete mixing and its evaluation," Journal of Chang'an University (Natural Science Edition), vol. 31, no. 2, pp. 101-105, 2011.

[30] L. Zhang, Z. Feng, and L. Zhao, "Test study of $1 \mathrm{~m} 3$ vibratory concrete mixer with double-horizontal shafts," Journal of Guangxi University (Natural Science Edition), vol. 38, no. 2, pp. 250-255, 2013.

[31] Y. Yao, J. Ni, and J. Li, "Stress-dependent water retention of granite residual soil and its implications for ground settlement," Computers and Geotechnics, vol. 129, Article ID 103835, 2021.

[32] H. Beitzel, Y. Charonnat, and M. Beitzel, "Assessment and classification of performance mixers," Materials and Structures, vol. 36, no. 4, pp. 250-264, 2003. 